\title{
ESTUDO FACIOLÓGICO DO SUPERGRUPO TUBARÃO NA REGIĀO DA BARROCADA (CACHOEIRA DO SUL - RS)
}

Milton Antonio A. Santos (UNISINOS)

Adail Ricardo Leister Gonçalves (UFSCar/São Carlos, SP)

Reinaldo Lorandi (UFSCar/São Carlos, SP)

Com a finalidade de estudo das fácies sedimentares da re gião da Barrocada, foram escolhidos, para descrição e interpretação, dois afloramentos (Af1 e Af2) pertencentes a sequência deposicional Tubarão (Formações Rio Bonito e Palermo) e três furos de sondagem (DU-03-RS, DU-06-RS e SD-06-RS) perfurados pela companhia de Pesqui sa de Recursos Minerais(CPRM-Superintendência Regional de Porto Ale gre) sendo os dois primeiros pertencentes ao convênio DNPM/CPRM e o terceiro ao Projeto são sepé.

A área de estudo encontra-se geologicamente localizada na sequência sedimentar da Bacia do Paraná e geograficamente no centro do Estado do Rio Grande do Sul. Os afloramentos Afl (Barroca da) e Af2 (Fonte) localizam-se respectivamente a $1 \mathrm{Km}$ antes do Posto da Fonte (lado esquerdo) e $300 \mathrm{~m}$ após o referido Posto (lado direito), na BR-290, sentido Porto Alegre - Uruguaiana enquanto que os fûros de sondagem foram abertos mais distantes da rodovia.

Foram identificadas as seguintes fácies:

FÁCIES DE CARVÃO E PELITOS CARBONOSOS - POr apresentar caracte rísticas de distribuição regional, consideramos esta fácie como um evento referencial (datum) para a interpretação faciológica das demais camadas sotopostas a esta.

o comportamento ambiental desta făcie é concordante com - proposto por Lavina et alii (1985) e Lopes et alii (1986), onde o ambiente de deposição foi desenvolvido em águas calmas, rasas,com o desenvolvimento de pântanos atrás de barreiras, estando esta fácie representada por pelitos maciços friáveis, de coloração cinza escura e camadas de carvão. Nos afloramentos essa fácie constitui a ba se, com espessura da camada variando entre 0,50 a 1,00 metro. 
FÁCIES DE PLANÍCIE DE MARÉ - Nestas fácies são encontradas areias grossas com estratificação cruzada truncada por ondas, de geo metria tabular, recobertos por camadas pelíticas maciças. Estes depó sitos são atualmente caracterizados pela razão existente entre areia e lama. Onde ocorre a predominância de areias grosseiras a lama preenche normalmente lentes côncavas para cima com poucos centímetros de diâmetro, onde ocorre um equilíbrio entre a quantidade de areia e lama, esta última forma camadas anastomosadas sobre as areias que são normalmente onduladas. Quando ocorre uma rarefação das areias es tas se apresentam como ondas famintas (starved ripples) ou então uma discreta laminação planar (Clifton, 1972). Nos depósitos em questão observa-se um equilíbrio entre a quantidade de areia e lama, e também por vezes um predomínio das lamas sobre as areias. Sobrepondo -se a estes depósitos encontramos uma camada de areias finas, bem se lecionadas, com uma espessura de aproximadamente $30 \mathrm{~cm}$, limpas e com estratificação cruzada ondulada de pequeno porte, o que nos sugere pouco predomínio da ação de ondas. Essa camada encontra-se truncada no topo por um período de não deposição, evidenciado por um "hardground", que se caracteriza por uma camada lateritica.

Acima deste, e com uma espessura de aproximadamente $60 \mathrm{~cm}$, encontramos areias siltosas. Na porção mais basal, há predominância da fração silte com incipientes estratificações cruzadas por ondas; já na porção mais central do corpo, a tendência é para o desaparecimento desta fração, com predomínio para as areias finas a muito finas, evidenciando a presença de cruzadas onduladas, unidirecionais e bidirecionais. A medida que chegamos ao topo, voltam novamente a pre dominar os siltes que mantêm as areias subordinadas sob a forma de corpos lenticulares. São observadas também neste pacote feições tais como superfície de reativação e estratificação do tipo "herring bone" acamadamento flaser e drape.

Em uma avaliação das estruturas citadas, as superfícies de reativação nos indicam uma interrupção no fluxo deposicional, ero são, e a volta da deposição em regiões sob a ação de marés. o contró le sobre a deposição e a erosão normalmente é determinado pela ação de correntes reversas, isto é, maré enchente e maré vazante, ou então para caracterizar mudanças na altura da lâmina de água(mais ou menos profunda) de fluxos unidirecionais (Weimer et alii 1982) o que, dentro do contexto estudado, nos parece mais razoável. Os fluxos bidire cionais ficam representados pela estratificação cruzada " espinha de peixe" (herring bone) que também é indicativo da fácies de planície de maré (Reineck e Singh, 1980). Quanto as lentes arenosas em cama das siltosas, sugerimos depósitos de "wavy linsen", considerando que cada camada de arenito constituía um evento de tempestade, envolvendo transpórte de areia em suspensão por fluxo de retorno (Morton, 1981; 
Galloway e Hobday, 1983).

FÁCIES DE HARD-GROUND BIOTURBADO - Caracteriza-se por uma cama da arenosa laterizada que sobrepõe-se a fácies anterior e tem como principal característica a evidência de atividade orgânica.

As estruturas orgânicas destacadas nesta fácies são icno fósseis, pertencentes aos icnogêneros Talassinöides, Planolites e Isopodicmus (Hantzschel, 1962). Por tratar-se de formas não verticais pro pomos a icnofácies Cruziana para estas estruturas, ficando as mesmas dentro do contexto paleoecológico proposto por Netto e Gonzaga (1985) .

FÁCIES DE SAND WAVE - Compreendendo um corpo de forma tabu lar (2D) com uma espessura superior a $5 \mathrm{~m}$, composto por areias médias a grossas não conglomeráticas e quartzosas, destacando em seu inte rior estratos cruzados tabulares unidirecionais. Nas porções mais distais estas estratificações passam a ser de baixo ângulo, ficando evidente a presença de "climbing ripples". A sand wave identificada nos afloramentos nos parece ser muito semelhante ao corpo arenoso proposto por Johnson (1980).

De acordo com Johnson (1980), bem como Nio (1986), a gênese desses corpos estaria vinculada a fortes correntes de maré como principal fonte energética. Entretanto, pensamos estar sua or $\underline{i}$ gem associada também, a depósitos com ação de ondas, principalmente ondas de tempestade, de acordo com o proposto por Lavina et alii (1985).

FÁCIES DE TEMPESTITOS - Esta fácie composta de arenitos com estratificação cruzada ondulada "hummocky" foi observada em dois dos três testemunhos de sondagem (SD-06-RS e DU-06-RS) e nos dois afloramentos analisados (Afl e Af2), com espessura variável em função de suas localizações no ambiente deposicional.

A estrutura "hummocky" que está caracterizada nesses locais como uma estratificação cruzada de muito baixo ângulo,microgra dação laminar e truncamento com grande comprimento de onda, apresen . ta indícios associativos com barras de costa afora. Tais indicios, obtidos em análises dos testemunhos de sondagem, são confirmados quan do se investiga os afloramentos, onde tais estruturas são identificadas em corpos lenticulares de arenitos médios a grossos típicos de barras e também, segundo Walker (1979), Dott e Bourgeois (1983)e La vina et alii (1985), pela presença de pelitos entre as camadas arenosas, indicando deposição abaixo do nível base das ondas normais , porém acima do nível base de ação das ondas de tempestade.

Em um dos furos descritos (SD-06-RS) foram identificadas bioturbações no topo deste depósito de tempestito, indicando, segun do Dott e Bourgeois (1982), uma maior frequência no aporte de areia. 
Por outro lado, segundo estes mesmos autores, sequências inteiras bioturbadas poderiam refletir a existência de intervalos de tempo mais longos entre os eventos de tempestade, o que não ocorre neste caso.

Em função da distribuição dos furos de sondagem e locali zação dos afloramentos optou-se por duas sequências de correlações estratigráficas uma envolvendo os furos SD-06-RS, DU-06-RS e Af1 (Barrocada), e outra contendo os furos SD-06-RS, DU-03-RS e Af2 (Fon te). Foi escolhida como DATUM, baseando-se em perfis de raio gama, uma camada de carvão, a qual é denominada CA (camada A).

As sequências de correlações aqui propostas, caracterizam eventos transgressivos, nas quais, em pelo menos dois dos três fü ros de sonda estudados nos é possivel destacar a presença de no minímo dois pulsos de subida ao nível do mar.

As transgressões, pelas medidas de paleocorrentes efetua das em Afl, indicam uma orientação NW - SE.

Por outro lado, nos é possível evidenciar a presença de um corpo arenoso de grandes proporções, que interpretamos como sendo a sand wave (DU-03-RS), nos demais furos ela se manifesta sempre em menores dimensões. A presença de camadas de carvão isoladas ou en tão associadas a pelitos, indicam recuos do nível do mar levandonos a crer que antes da transgressão definitiva (Formação Palermo) ocorreu vários pulsos transgressivos e regressivos. Nestes intervalos de recuo do mar desenvolviam-se, nesta região de transição, depósitos lagunares, de marés, aportando também sedimentos de origem continental. A região de mar profundo (costa afora), sem a presença das barras, é caracterizada também no furo acima mencionado, sendo que nos demais (SD-06-RS e DU-06-RS) esta se caracteriza mais pela presença dos depósitos de tempestitos.

Destacamos também, a presença de icnofösseis associados aos depósitos de tempestade, sendo que no furo DU-06-RS nos foi pos sível reconhecer a icnofácies skolitos (Netto e Gonzaga, 1985).

o estudo dos afloramentos e a analogia com os furos de sondagem, nos levam a interpretar as sequências em questão como per tencentes a um evento de características predominantemente transgressivas.

Partindo do pressuposto que havia um sistema deposicio nal em equilíbrio, composto pelo mar, ilhas de barreira, lagunas e rios, conforme Lavina et alii (1985), cremos ser os afloramentos em questão pertencentes a um sistema de planicies onde atuavam marés, chegavam rios e também havia o desenvolvimento de turfeiras.Tal sis tema foi gradativamente afogado pelo mar que, em pulsos, transgressivos e regressivos, foi pouco a pouco cobrindo estas feições, vindo finalmente a instalar-se por completo, gerando o que conhecemos com o nome de Formação Palermo. O sistema de planicies, anteriormente cí 
tado, compreende o que conhecemos como Formação Rio Bonito, à qual encontramos associado carvão, feições deltáicaś, etc. Pelas estrutú ras citadas e a interação dos depósitos arenosos e lamosos, acreaitamos ser o contexto deposicional destas planicies um ambiente estuarino, onde pode se notar a ação de marés, mas não seư predomínio. Ao longo do tempo geológico este sistema foi afogado pelo mar do Pa lermo, conforme indica as sand waves e os depósitos de tempestade que correspondem as barras de costa afora (off shore).

Antes de ocorrer a transgressão definitiva, ocorreram pa radas no processo deposicional transgressivo o que, permitiu $\circ$ de senvolvimento de turfeiras e atividade orgânica, representadas pelas estruturas sedimentares organógenas existentes no hara ground que situa-se abaixo da sand wave.

REFERÊNCIAS BIBLIOGRÁFICAS

CLIFTON, H.E. 1982. Estuarine deposits. In: Scholle, P.A. and Spearing, D. (ed.), Sandstone Depositional Environments, Ist ed., American Association of Petroleun Geologists, p. 179-189.

DOTT, R.H. \& BOURGEOIS, J. 1982. Hummocky stratification: signifi= cance of its variable beding sequences. Geol. Soc. Am. Bull., 93: 66380 .

GALLOWAY, W.E. \& HOBDAY, D.K. 1983. Terrigeneous clastic depositional sys tems. New York, Springer - Verlag. 423p.

HANTZSCHEL, $W .1962$. Trace fossils and problematica. In: Moore, R.C. (ed), Treatise on Invertebrate Paleontology-Part $w$, Geol. Soc. of Ameri ca. p. 177-245.

-

JOHNSON, H.D. 1980. Shallow siliciclastic seas. In: Reading, H. G. Sedimentary Environments and Facies. London, Black-Well Scientific Publications, p. 207-58.

LAVINA, E.L.; NOWATZKI, C.H.; SANTOS, M.A.A. \& LEÃO, H.Z. 1985. Ambientes de sedimentação do Super-Grupo Tubarão na região de Cachoe 1 ra do Sui, R.S. São Leopoldo. Acta Geológica Leopoldensia, (21) : 5-76:

LOPES, R.C.; LAVINA, E.L. \& SIGNORELLI, N. 1986.Fácies sedimentares e evolução paleoambiental do Super-Grupo Tubarão na borda leste da Bacia do Paraná. Uma seção regional nos Estados do Rio Grande do Sul e Santa Catarina: In: CONGRESSO BRASILEIRO DE GEOLOGIA, 34, Goiânia, 1986. Anais... Goiânia: SBG, v. 1, p. 206-18. 
MORTON, R.A. 1981. Formation of storm deposits by wind-forced cur rents in the Gulf of Mexico and North Sea. Spec. Pub., Int. Assoc. Sed iment., 5:385-96.

NETTO, R.G. \& GONZAGA, T.D. 1985. Paleoicnologia do Grupo Guatá (Sú per-Grupo Tubarão) nos sedimentitos da Mina do Iruí, Cachoeira do Sul, R.S. Acta Geológica Leopoldensia, 21:77-102.

NIO SWIE-DJIN. 1976. Marine transgressions as a factor in the forma tion of sandwave complexes. Geol. Mi jn., 55 (1-2):18-40.

REINECK, H.E. \& SINGH, I.B. 1980. Depositional sedimentary environments., 2nd, rev. and update ed., Berlin, Springer-Verlag, 549p.

WALKER, R.G. 1979. Shallow marine sands. In: Walker, R.G.(ed), Facies models. Geological Association of Canada, Reprint Series,Geoscience Ca nada, 1:75-90.

WEIMER, R.J.; HOWARD, J.D. \& LINDSAY, D.R. 1982. Tidal Flats and Associated Tidal Channels, In: Scholle, P.A. and Spearing, D. (ed), Sandstone Depositional Environments, 1st ed., American Association of Pe troleum Geologists, p. 191-245. 